\title{
Human Gut Microbiome: an Imperative Element for Human Survival
}

\author{
Monika, Manoj Kumar Verma, Vasim Ahmed and Nar Singh Chauhan* \\ Department of Biochemistry, Maharshi Dayanand University, India
}

Submission: June 27, 2017; Published: July 26, 2017

*Corresponding author: Nar Singh Chauhan, Department of Biochemistry, Maharshi Dayanand University, Haryana, India, Email: nschauhan@ mdurohtak.ac.in

\section{Overview}

Human gut contains plethora of microbes providing a platform for functional and metabolic interaction between host and microbiota. The human gastro-intestinal tract is known to have trillions of bacterial cells, more than the human cells by approximately a factor of 10 [1]. A major fraction of microbes $(<70 \%)$ identified from human body are found to be colonized in the gastro-intestinal tract [1]. Gut microbial community is dominated by strict anaerobes outnumbering the facultative anaerobes and aerobes by a factor of two to three [2]. Bacteroidetes and Firmicutes are dominant phyotypes among reported microbial groups from human gut [3]. Different human gut microbial studies have reported varying number of bacterial species, with an average of 500-1000 [4]. Colonization of these microbes begins with birth and shows maximum diversity in the healthy adult age [5]. Higher vertebrates were coevolved with their microbiota with the interactions between the gastrointestinal tract and microbial communities. Therefore, any changes in the lifestyle, diet, environmental conditions directly modulate the microbiota [6]. Recent findings have stepped out to decipher change the microbial environment with the use of antibiotics, fecal transplantation, prebiotic and probiotic treatments [7]. Human gut microbiome act like a superorganism or holobiont within human body and found essential for human health. A number of association studies link human nutrition and health with metabolic capacity of gut microbiota [8]. There occurs a commensalism between gut microbiota and host, where gut microbes use the substrate for fermentation fulfilling the nutrient and energy needs of the host. Bacterial cross-feeding is predominant mechanism leading to the degradation of the complex and undigested food materials into energy-providing metabolites [9]. Gut microbiota has been found to change the biochemical aspects of the diet thereby playing a role in host health and diseases. Gut microbes are involved in many metabolic pathways providing essential metabolites for the human body. The human gut microbiome have diverse physiological roles like immune system maintenance [10], vitamin production
[11], digestion [12], energy homeostasis [13], angiogenesis [14], metabolites synthesis [15] and maintenance of intestinal barrier integrity [16]. The role of microbiota in affecting host physiology, from nutritional aspects to the diseases such as rheumatoid arthritis, cardiovascular diseases, obesity, and diabetes has been well proven [17]. Gut microbiota is an easy target to treat or prevent a disease. Specific bacterial groups are analysed in healthy individuals along with those of patients with diverse disease phenotypes [18].

Recent studies showed that identification of particular bacteria may be a responsive indicator of variations in human health as microbial dissimilarity goes beyond the level of dissimilarity in recognized metabolic genes and pathways. Dissimilarity and variations in human microbiota in several body habitats will lead to identification of next-generation diagnostics and therapeutic means [19]. The human microbiome might simplify the prognosis of patients of outcomes for various physiologic parameters like systemic immune responses, pain signaling, whole body metabolism and energy harvest [20]. The knowledge of interactions between microbiota and host metabolism as well as modification of microbial ecology is really beneficial to have effective therapeutic treatments for many diet related diseases in near future.

\section{References}

1. Whitman WB, Coleman DC, Wiebe WJ (1998) Prokaryotes: The Unseen Majority. Proc Natl Acad Sci 95(12): 6578-6583.

2. Harris MA, Reddy CA, Carter GR (1976) Anaerobic Bacteria from the Large Intestine of Mice. Appl Environ Microbiol 31(6): 907-912.

3. Schloss PD, Handelsman J (2004) Status of the Microbial Census Microbiol Mol Biol Rev 68(4): 686-691.

4. Salonen A, Nikkilä J, Jalanka-Tuovinen J, Immonen O, Rajilić Stojanović M, et al. (2010) Comparative Analysis of Fecal DNA Extraction Methods with Phylogenetic Microarray: Effective Recovery of Bacterial and Archaeal DNA Using Mechanical Cell Lysis. J Microbiol Methods 81(2): 127-134. 
5. Wall R, Ross RP, Ryan CA, Hussey S, Murphy B, et al. (2009) Role of Gut Microbiota in Early Infant Development. Clin Med Pediatr 3: 45-54.

6. De Filippo C, Cavalieri D, Di Paola M, Ramazzotti M, Poullet JB, et al. (2010) Impact of Diet in Shaping Gut Microbiota Revealed by a Comparative Study in Children from Europe and Rural Africa. Proc Natl Acad Sci 107(33): 14691-14696.

7. Marchesi JR, Adams DH, Fava F, Hermes GD, Hirschfield GM, et al. (2016) The gut microbiota and host health: a new clinical frontier. Gut 65(2): 330-339.

8. Flint HJ, Scott KP, Louis P, Duncan SH (2012) The Role of the Gut Microbiota in Nutrition and Health. Nat Rev Gastroenterol Hepatol 9(10): 577-589

9. Louis P, Hold GL, Flint HJ (2014) The Gut Microbiota, Bacterial Metabolites and Colorectal Cancer. Nat Rev Microbiol 12(10): 661-672.

10. Kamada N, Núñez G (2013) Role of the Gut Microbiota in the Development and Function of Lymphoid Cells. J Immunol 190(4): 1389-1395.

11. Magnúsdóttir S, Ravcheev D, Thiele I (2015) Systematic Genome Assessment of B-Vitamin Biosynthesis Suggests Co-Operation among Gut Microbes Front Genet 6: 148 .

12. Acheson DWK, Luccioli S (2004) Microbial-Gut Interactions in Health and Disease. Mucosal Immune Responses. Best Practice and Research. Best Pract Res Clin Gastroenterol 18(2): 387-404.
13. Koboziev I,Webb CR, Furr KL, Grisham MB (2014) Role of the Enteric Microbiota in Intestinal Homeostasis and Inflammation. Free Radic Biol Med 68: 122-133.

14. Stappenbeck TS, Hooper LV, Gordon JI (2002) Developmental Regulation of Intestinal Angiogenesis by Indigenous Microbes via Paneth Cells. Proc Natl Acad Sci 99(24): 15451-15455.

15. Guarner F, Malagelada JR (2003) Gut Flora in Health and Disease. Lancet 361(9356): 512-519.

16. Sharma R, Young C, Neu J (2010) Molecular Modulation of Intestinal Epithelial Barrier: Contribution of Microbiota. J Biomed Biotechnol 2010: 305879.

17. Hawrelak JA, Myers SP (2004) The Causes of Intestinal Dysbiosis: A Review. Altern Med Rev 9(2): 180-197.

18. Fujimura KE, Slusher NA, Cabana MD, Lynch SV (2010) Role of the gut microbiota in defining human health. Expert Rev Anti Infect Ther 8(4): 435-454.

19. Lozupone CA, Stombaugh JI, Gordon JI, Jansson JK, Knight R (2012) Diversity, stability and resilience of the human gut microbiota. Nature 489(7415): 220-230

20. Devaraj S, Hemarajata P, Versalovic J (2013) The Human Gut Microbiome and Body Metabolism: Implications for Obesity and Diabetes. Clin Chem 59(4): 617-628.

\section{Your next submission with Juniper Publishers will reach you the below assets}

- Quality Editorial service 